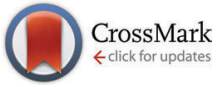

Cite this: J. Mater. Chem. C, 2016, 4,6873

\title{
High mobility polycrystalline indium oxide thin-film transistors by means of plasma-enhanced atomic layer deposition $\uparrow$
}

\author{
H.-I. Yeom, J. B. Ko, G. Mun and S.-H. Ko Park*
}

\begin{abstract}
Indium oxide thin films are deposited via plasma-enhanced atomic layer deposition (PEALD) to exploit their potential as a semiconductor in high mobility thin-film transistors (TFTs), which are suitable for fast driving applications such as high resolution displays. The films are successfully grown by the reaction between an $\mathrm{Et}_{2} \mathrm{lnN}\left(\mathrm{SiMe}_{3}\right)_{2}$ liquid precursor and oxygen plasma at temperatures ranging from $100{ }^{\circ} \mathrm{C}$ to $250{ }^{\circ} \mathrm{C}$ giving a saturated growth rate value of $\sim 1.45 \AA$ per cycle at the ALD window with precisely controlled thickness and uniformity. The plasma reaction enhances the film growth rate and changes the electrical properties of the films. Depending on the substrate temperatures, each film has a different chemical composition, thereby showing different electrical characteristics. Indium oxide films grown by PEALD show a lower carrier density of $\sim 4 \times 10^{19} \mathrm{~cm}^{-3}$ than those prepared by thermal ALD due to the reactive oxygen plasma source in the former. Offering the precise control of thickness and high quality of indium oxide grown by PEALD, and with a proper post thermal-annealing and passivation process, the possibility of exploiting the potential of semiconductor characteristics of indium oxide is verified from bottom-gate coplanar structured TFTs, which exhibit a high mobility as high as $39.2 \mathrm{~cm}^{2} \mathrm{~V}^{-1} \mathrm{~s}^{-1}$, a turnon voltage value of $-1.18 \mathrm{~V}$, and a sub-threshold voltage of $0.27 \mathrm{~V} \mathrm{dec}^{-1}$ in a linear region. On the basis of this outstanding performance, the PEALD-InO $\mathrm{I}_{x}$ TFTs developed in this study would be suitable for diverse microelectronic devices.
\end{abstract}

Received 8th February 2016, Accepted 22nd June 2016

DOI: $10.1039 / c 6 t c 00580 b$

www.rsc.org/MaterialsC

\section{Introduction}

Indium oxide $\left(\operatorname{InO}_{x}\right)$ has a mobility as high as $160 \mathrm{~cm}^{2} \mathrm{~V}^{-1} \mathrm{~s}^{-1}$ in a single crystalline structure and has been intensively studied for its high electrical conductivity and optical transparency with a wide band gap $(\sim 3.75 \mathrm{eV}) .{ }^{1,2}$ Due to their excellent carrier transport capability, indium oxide thin films have been used for various kinds of optoelectronic applications. ${ }^{3-5}$ Notably, with increasing demand for high mobility thin-film transistors (TFTs) to drive ultra-high resolution displays, there have been many attempts to fabricate indium oxide TFTs, using approaches such as sputtering, ${ }^{6,7}$ reactive evaporation, ${ }^{8}$ pulsed electron beam deposition, ${ }^{9}$ and solution processes. ${ }^{10-12}$ Since most InO $_{x}$ TFTs fabricated by physical deposition showed worse TFT performance in terms of field effective mobility, sub-threshold swing (S.S.), and

Department of Materials Science and Engineering,

Korea Advanced Institute of Science and Technology (KAIST), 291 Daehak-ro,

Yuseong-gu, Daejeon 305-701, Republic of Korea. E-mail: shkp@kaist.ac.kr

$\dagger$ Electronic supplementary information (ESI) available: $\mathrm{InO}_{x}$ film growth rate as a function of the reactant pulsing time (Fig. S1), film thickness as a function of the number of ALD cycles (Fig. S2), XPS results of as-deposited $\mathrm{InO}_{x}$ films with different deposition temperatures (Fig. S3-S5 and Table S1). See DOI: 10.1039/ c6tc00580b turn-on voltage $\left(V_{\text {on }}\right),{ }^{6,8}$ thicker films of $\mathrm{InO}_{x}$ have been employed to achieve high mobility. Most TFTs with such thick $\mathrm{InO}_{x}$ semiconductors, however, show a huge negative shifted $V_{\text {on }}$ value as well as a low on/off current ratio. ${ }^{7,9}$ Although $\mathrm{InO}_{x}$ TFTs processed using a solution precursor exhibit a relatively higher mobility of more than $20 \mathrm{~cm}^{2} \mathrm{~V}^{-1} \mathrm{~s}^{-1}$ compared to that of other solution processed oxide TFTs, their performances should be improved for application in an actual display. ${ }^{11,12}$ For the practical application of $\mathrm{InO}_{x}$ to TFTs in high resolution displays, not only high mobility but also other parameters such as $V_{\text {th }}$, on/off ratio, and subthreshold swing (S.S.) should be carefully evaluated. ${ }^{7,13,14}$

The atomic layer deposition (ALD) process, whereby a film is deposited by a self-limiting reaction on the substrates to yield a uniform film over a large area with a precisely controlled thickness is a promising tool to prepare conformal and high quality films even with reduced thicknesses. There have been many efforts to obtain $\mathrm{InO}_{x}$ films by ALD using various precursors and reactants. The properties of films are considerably affected by the sources. The first reported ALD growth of an $\mathrm{InO}_{x}$ film utilizing $\mathrm{InCl}_{3}$ required a relatively high deposition temperature $\left(\sim 500{ }^{\circ} \mathrm{C}\right)$ and showed a low growth rate $(<0.3 \AA$ per cycle). ${ }^{15}$ Other solid indium precursors such as $\operatorname{In}(\mathrm{acac})_{3},{ }^{16}$ $\beta$-diketonates, ${ }^{17}$ and trimethyl indium (TMIn) ${ }^{18}$ also exhibited 
low growth rates $(<0.4 \AA$ per cycle). A fast growth rate $(1.3-2.0 \AA$ per cycle) was obtained with cyclopentadienyl indium (InCp) and ozone with good conformality on anodic aluminium oxide membranes, which have an aspect ratio, $L / d$, of $350 .{ }^{19}$ These solid precursors, however, hindered the application of ALD processed $\mathrm{InO}_{x}$ to the semiconductor layer of TFTs for displays due to not only a low vapor pressure but also difficulty in keeping a constant vapor pressure. Most display fabrication strategies adopt a substrate size larger than $(730 \times 920) \mathrm{mm}^{2}$ and liquid precursors are easily supplied with a constant large amount of vapor. ${ }^{20}$ Furthermore, the electrical properties of $\mathrm{InO}_{x}$ films grown by these precursors have not been thoroughly investigated.

Recently, Maeng et al. used diethyl[bis(trimethylsilyl)amido]indium $\left(\mathrm{Et}_{2} \mathrm{InN}\left(\mathrm{SiMe}_{3}\right)_{2}\right)$, [3-(dimethyl-amino)]dimethyl-indium (DADI), and triethyl-indium (TEIn) liquid precursors for the growth of $\mathrm{InO}_{x}$ films using ozone. ${ }^{21}$ They reported a relatively high growth rate $(\sim 0.8 \AA$ per cycle) and film resistivity as low as $8 \times 10^{-5} \Omega \mathrm{cm}$. These $\mathrm{InO}_{x}$ films, however, were studied as a transparent conducting oxide (TCO) for their low resistivity, not as semiconducting films.

In this work, we demonstrate a plasma-enhanced ALD (PEALD) process using a liquid source of $\mathrm{Et}_{2} \operatorname{InN}\left(\mathrm{SiMe}_{3}\right)_{2}$ and oxygen plasma for depositing $\mathrm{InO}_{x}$ films at different growth temperatures for application to the active layer of TFTs. We examined the optical, chemical, and electrical characteristics of the films with various tools. Nano-crystalline ultra-thin indium oxide films by PEALD were successfully adopted in TFTs and showed high electrical performance as a switching and driving device for an actual display.

\section{Experimental}

Indium oxide films were deposited by a 6 " substrate sized Genie ALD system using $\mathrm{Et}_{2} \mathrm{InN}\left(\mathrm{SiMe}_{3}\right)_{2}$ provided by UP Chemical Co., Ltd and oxygen plasma as the precursors of In and oxygen, respectively. The indium precursor was contained in a bubbler type canister at $40{ }^{\circ} \mathrm{C}$. Ar gas was used as a carrier gas ( $80 \mathrm{sccm}$ ) as well as a purging gas $(160 \mathrm{sccm})$. And $\mathrm{O}_{2}$ gas flow was maintained at $60 \mathrm{sccm}$. Sequential steps of deposition included introducing the indium precursor to the reactor chamber for $2.5 \mathrm{~s}$, Ar purge for $6 \mathrm{~s}$, oxygen plasma for $1.5 \mathrm{~s}$, and Ar purge for $1.5 \mathrm{~s}$ at a working pressure of 3 Torr and a plasma power of $100 \mathrm{~W}$. The $25 \mathrm{~nm}$-thick $\mathrm{InO}_{x}$ films deposited on $\mathrm{Si}, \mathrm{Al}_{2} \mathrm{O}_{3} / \mathrm{Si}(100)$, and glass substrates were annealed under an $\mathrm{O}_{2}$ atmosphere for 2 hours. Both as-deposited and annealed films were analyzed using various tools. The thickness of the films deposited on the $\mathrm{Si}(100)$ substrate was measured using a J. A. Woolam Co. Alpha-SE ellipsometer. To clarify the crystallinity of the films, X-ray diffraction patterns were obtained with a theta/2theta scan mode using a $\mathrm{Cu} \mathrm{K} \alpha$ X-ray source. To analyze the elemental composition of the bulk films, X-ray photoelectron spectroscopy (XPS) analysis was performed using K-alpha (Thermo VG Scientific) after brief sputtering to remove contaminants from the surface of the samples. The Hall mobility, resistivity, and carrier density for the films deposited on glass substrates were all set by Hall measurements (Accent HL 5500 Hall System). The optical properties including the transmittance and absorption spectrum were obtained from UV-visible spectroscopy (UV-vis) analysis. All the films were carefully examined by calibration with a reference glass that has no absorbance within a photon energy range of $2-4.5 \mathrm{eV}$.

The bottom-gate coplanar TFTs were fabricated on indium-tinoxide (ITO) glass. First, $150 \mathrm{~nm}$-thick ITO glass was patterned as a gate by wet etching. After an $\mathrm{Al}_{2} \mathrm{O}_{3}$ film of $175 \mathrm{~nm}$ was deposited by means of ALD at $150{ }^{\circ} \mathrm{C}$ as a gate insulator, a source/drain ITO was deposited by radio frequency (RF) sputtering at $250 \mathrm{~W}$, followed by vacuum annealing at a temperature of $250{ }^{\circ} \mathrm{C}$ for 2 hours to lower the resistivity of ITO. After patterning the source/drain ITO by wet etching, PEALD-InO ${ }_{x}$ was grown to $5 \mathrm{~nm}$-thick. Deposited $\mathrm{InO}_{x}$ films were patterned, followed by annealing at a temperature of $350{ }^{\circ} \mathrm{C}$ in an $\mathrm{O}_{2}$ condition for 2 hours. As a final step, silicon oxide, which consisted of double layered silicon oxide, the first and second layer deposited under low and high process pressures, respectively, was deposited by plasma enhanced chemical vapor deposition (PECVD) at $300{ }^{\circ} \mathrm{C}$ to passivate the whole device and the devices were annealed at $300{ }^{\circ} \mathrm{C}$ under vacuum. The key factor of passivation process is the control of hydrogen incorporation into the active layer. The purpose of the first layer of $\mathrm{SiO}_{2}$ deposition under low pressure is not to induce plasma damage on the back channel region during the PECVD process. The second layer under high pressure contains less hydrogen content, thereby minimizing hydrogen diffusion in to the active layer during thermal annealing. A JEM-2100F transmission electron microscope (TEM) with a $200 \mathrm{kV}$ electron beam energy was used to verify the crystallinity of the thin $5 \mathrm{~nm}$-thick film, which was actually adopted in the TFTs. The electrical characteristics of InO $_{x}$ TFTs were analyzed with transfer curves by HP 4156A. The output and transfer curves were obtained and electrical parameters were extracted from the curves.

\section{Results and discussion}

To determine the optimum dose of the indium precursor and oxygen plasma for the self-limiting reaction, we deposited indium oxide $\left(\mathrm{InO}_{x}\right)$ films on a $\mathrm{Si}(100)$ substrate with an increasing precursor amount and reactant pulsing time at a temperature of $200{ }^{\circ} \mathrm{C}$ (Fig. 1). As the indium precursor pulsing time increases, the growth per cycle (GPC) is sharply increased and it saturated at $\sim 1.45$ A per cycle with a feeding time of over 2 seconds. The GPC is saturated above $1.5 \mathrm{~s}$ of oxygen plasma pulsing time (Fig. $\mathrm{S} 1 \mathrm{in}$ the ESI $\dagger)$. The deposition rate $(\sim 1.45 \AA$ per cycle) is much higher compared to the values (less than $0.3^{15}$ and $0.4 \AA$ per cycle $^{16-18}$ ) obtained using other indium precursors.

The value is even higher than those $\left(0.7^{22}\right.$ and $0.8 \AA$ per cycle $^{21}$ ) reported from the same indium source as ours but with the use of a different oxygen source, water and ozone, for the ALD-InO ${ }_{x}$ growth process. While the less reactive water or ozone reactant would not completely finish the 2nd half 
(a)
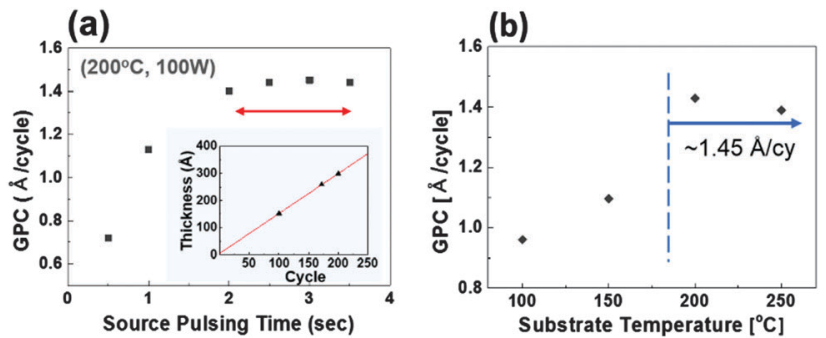

Fig. 1 Dependency of growth rate of $\ln O_{x}$ film deposited by PEALD as a function of (a) indium precursor pulsing time and (b) substrate temperature. The inset figure in (a) shows the film thickness with an increasing number of process cycles.

reaction with the chemisorbed indium precursor for ALD, the increasing reactive sites of the chemisorbed precursor on the surface of the film by virtue of the strong oxidant, oxygen plasma, results in a higher film growth rate than that seen with the thermal ALD process. ${ }^{23-25}$ The inset in Fig. 1(a) shows a near-perfect linear fitting to the graph with the ALD cycle number versus film thickness at $200{ }^{\circ} \mathrm{C}$. The film thickness was precisely controlled by the number of process cycles at other deposition temperatures, which ensures the self-limiting reaction (Fig. S2 in the ESI $\dagger$ ). The GPC at various substrate temperatures is shown in Fig. 1(b). The ALD window is found with an almost constant GPC value of $1.45 \AA$ A per cycle within $200-250{ }^{\circ} \mathrm{C}$, while a substantially lower GPC value is obtained below $150{ }^{\circ} \mathrm{C}$. At the temperature below the ALD window, incomplete reactions related with less surface chemisorption of the precursor, surface chemical reactions, and other factors could occur owing to the insufficient thermal energy ${ }^{26,27}$ Small decreases in the GPC between $200{ }^{\circ} \mathrm{C}$ and $250{ }^{\circ} \mathrm{C}$ are attributed to the slight decreasing number of reaction sites. ${ }^{28,29}$

We scrutinized XPS spectra to obtain information about each film and characterize the film properties. The surfaces of the samples were sputtered using an $\mathrm{Ar}^{+}$ion beam to remove surface contaminants. Table 1 displays the atomic percentage of each $\mathrm{InO}_{x}$ film annealed at $350{ }^{\circ} \mathrm{C}$ under $\mathrm{O}_{2}$ conditions, which was extracted from the XPS survey spectra. While the carbon content is higher than $2 \%$ in the case of films deposited at temperatures of $150{ }^{\circ} \mathrm{C}$ and $100{ }^{\circ} \mathrm{C}$, the content from the films grown above $200{ }^{\circ} \mathrm{C}$ was almost negligible (Fig. 2(a)). We ascribe the origin of carbon contamination for the relatively low temperature process to the incomplete oxidation of methyl groups bonded to Si under oxygen plasma owing to the insufficient fragmentation of ligands of indium precursor. Another noticeable aspect is the amount of $\mathrm{Si}$ atoms incorporated into the $\mathrm{InO}_{x}$ films increased up to $3.38 \%$ with increasing deposition temperature,

Table 1 The percentage of each atom in $\operatorname{lnO}_{x}$ films after annealing at $350{ }^{\circ} \mathrm{C}$ in $\mathrm{O}_{2}$ conditions calculated from the XPS survey spectra

\begin{tabular}{lllll}
\hline Deposition temperature $\left({ }^{\circ} \mathrm{C}\right)$ & In $(\%)$ & O (\%) & Si (\%) & C (\%) \\
\hline 100 & 36.40 & 58.03 & 1.64 & 3.92 \\
150 & 36.65 & 59.24 & 1.69 & 2.45 \\
200 & 37.67 & 60.03 & 2.30 & - \\
250 & 36.40 & 60.22 & 3.38 & -
\end{tabular}

(a)

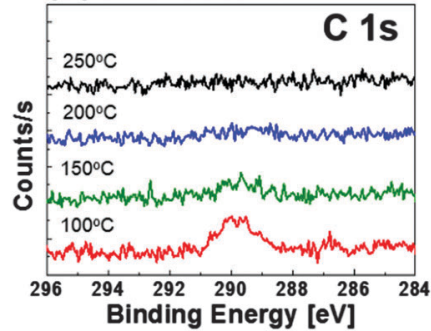

(b)

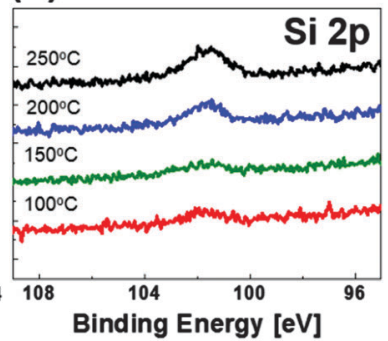

Fig. 2 (a) $\mathrm{C} 1 \mathrm{~s}$ and (b) Si $2 \mathrm{p}$ peaks of the annealed $\mathrm{InO}_{x}$ films measured by XPS with various deposition temperatures.

resulting in unintentional doping, as shown by the Si $2 \mathrm{p}$ peak of the bulk $\mathrm{InO}_{x}$ films (Fig. 2(b)). Maeng et al. reported that $\mathrm{Si}$ is completely eliminated from $\mathrm{InO}_{x}$ films grown by thermal ALD using the same In precursor and water. ${ }^{22}$ In thermal ALD, organic ligands bonded to the metal of the precursor are exchanged with each other by means of nucleophilic substitution of water to give $\mathrm{NHSi}\left(\mathrm{CH}_{3}\right)_{2}$ as a by-product. The PEALD process with excessive oxygen plasma energy, however, would break weak $\mathrm{Si}-\mathrm{N}$ bonds and $\mathrm{Si}-\mathrm{C}$ bonds in the ligands of the indium precursors at elevated temperatures, resulting in incorporation of non-volatile by-products of silicon oxide in the $\mathrm{InO}_{x}$ films. This is supported by the finding that nitrogen atoms, which bond indium and silicon atoms to the indium precursor, are not detected from any other as-deposited films prepared at any of the growth temperatures since the oxidized compounds of $\mathrm{N}$ are volatile (Fig. S3 in the ESI $\dagger$ ). The silicon oxide contained in the oxide semiconductor is known as a carrier suppressor for restraining the formation of oxygen vacancies in oxide semiconductors. ${ }^{30}$ We expect that the $\mathrm{InO}_{x}$ film prepared by PEALD using an indium precursor without a $\mathrm{Si}$ moiety would give a relatively higher carrier density than the present $\mathrm{InO}_{x}$ films with $\mathrm{Si}$.

To further investigate the stoichiometry of the annealed $\mathrm{InO}_{x}$ films, we deconvoluted the $\mathrm{O} 1 \mathrm{~s}$ peak near $530 \mathrm{eV}$ as illustrated in Fig. $3 .^{22,31}$ It is widely known that the binding energy of oxygen near oxygen vacancies $\left(V_{O}\right)$ in a metal oxide or $\mathrm{OH}$ - and OC-related oxygen is larger than that of typical oxygen in a metal oxide. In the films grown below the substrate temperature of $150{ }^{\circ} \mathrm{C}$, there appear shoulders located at larger binding energies than that of the main $\mathrm{O} 1 \mathrm{~s}$ peak, relating to the carbon impurities. We divided the $\mathrm{O} 1 \mathrm{~s}$ peak into three Gaussian curves to analyze the amount of each oxygen species. The area of each graph, which is indicated in Table 2, denotes the concentration of each species. The ratio of oxygen deficient bonding increased up to $34.03 \%$ with increasing temperature. In the case of $\mathrm{InO}_{x}$ film growth, a thermodynamic equilibrium condition induces an increase of the vapor pressure of oxygen as the temperature increases, giving rise to a generation of oxygen deficiencies in the films. ${ }^{18}$ As a result, the binding energy of the In $3 \mathrm{~d}$ peak is slightly shifted from $444.43 \mathrm{eV}$ to $444.13 \mathrm{eV}$ as the temperature increases from $100{ }^{\circ} \mathrm{C}$ to $250{ }^{\circ} \mathrm{C}$ (Fig. S4 in the ESI $\dagger$ ). Since metal to oxygen bonding is stronger than In- $\mathrm{V}_{\mathrm{O}}-\mathrm{In}$ bonding, indium atoms in the $\mathrm{InO}_{x}$ film are 


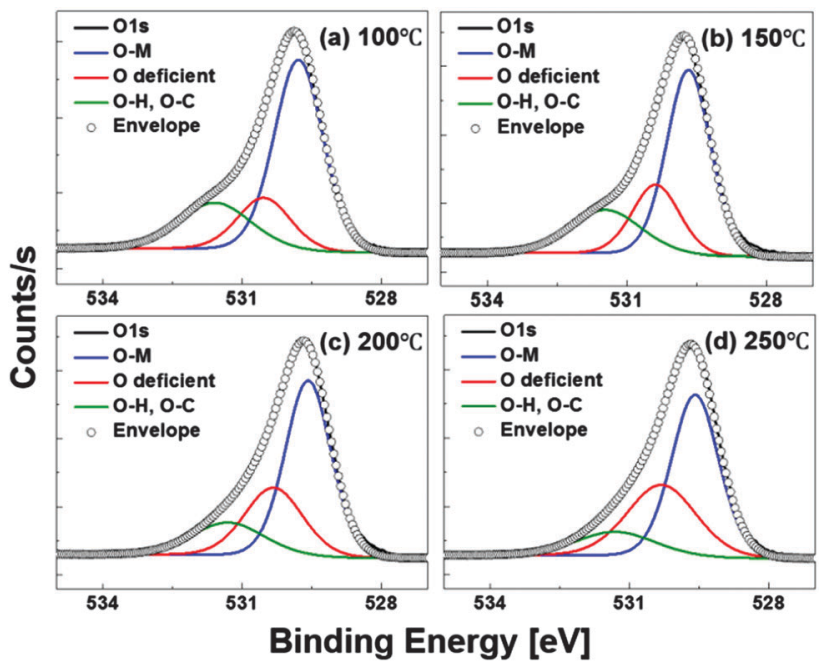

Fig. 3 The deconvoluted $O$ 1s XPS spectra of bulk $\ln O_{x}$ films with different deposition temperatures after annealing. The black line is experimental data and the black circle is a curve that is integrated with three fitted Gaussian lines. The blue, green, and red lines indicate $\mathrm{O}-\mathrm{M}, \mathrm{O}$ deficient, and $\mathrm{OC}$ - or $\mathrm{OH}$-related bonding, respectively.

Table 2 Calculated concentration of each $\mathrm{O}-\mathrm{M}, \mathrm{O}$ deficient, and $\mathrm{O}-\mathrm{H}$, $\mathrm{O}-\mathrm{C}$ bonding from deconvoluted $\mathrm{O}$ 1s XPS peaks

\begin{tabular}{llll}
\hline Deposition temperature $\left({ }^{\circ} \mathrm{C}\right)$ & $\mathrm{O}-\mathrm{M}(\%)$ & $\mathrm{O}$ deficient $(\%)$ & $\mathrm{O}-\mathrm{H}, \mathrm{O}-\mathrm{C}(\%)$ \\
\hline 100 & 60.98 & 17.68 & 21.34 \\
150 & 56.22 & 22.63 & 21.14 \\
200 & 56.18 & 27.53 & 16.29 \\
250 & 53.20 & 34.03 & 12.77
\end{tabular}

more likely to bond with oxygen at lower deposition temperatures, yielding a smaller amount of oxygen vacancies. It is found that the as-deposited films show an analogous tendency to the annealed films as described in Table S1 (see the ESI $\dagger$ ). The main $\mathrm{O}$ 1s peaks, however, are shifted to a higher binding energy compared to those from films annealed under $\mathrm{O}_{2}$, which indicates much more oxygen deficient species are involved in the as-deposited films (Fig. S5 in the ESI $†$ ).

The crystallinity of the $\mathrm{InO}_{x}$ films is clarified by their XRD patterns, as shown in Fig. 4. The as-deposited films show an amorphous phase at all deposition temperatures of $100-250^{\circ} \mathrm{C}$. The high growth rate often fails to provide sufficient surface (a) As-deposited

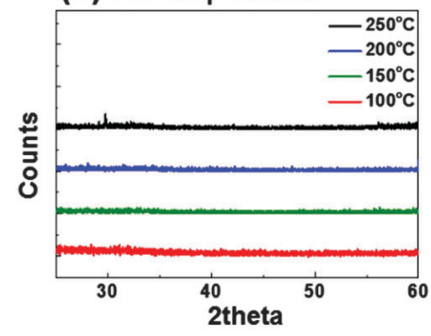

\section{(b) Annealed}

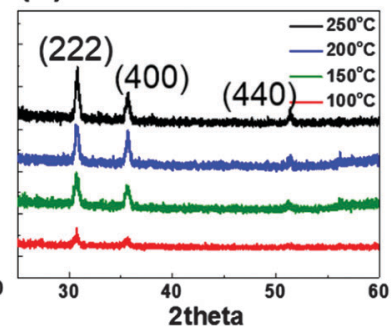

Fig. 4 XRD data of (a) as-deposited and (b) annealed $\operatorname{lnO}_{x}$ films on alumina/Si substrates at different deposition temperatures. diffusion time to move to a thermodynamically favorable position. In this case, atoms can be kinetically buried by subsequently depositing atoms before they find low energy sites, resulting in a less or non-crystallized film. For example, $\mathrm{InO}_{x}$ grown by thermal ALD using TMIn $^{18}$ or the same precursor ${ }^{22}$ as us and water resulted in a nano-crystalline phase at a very low growth rate of 0.39 and $0.7 \AA$ A per cycle, respectively. Meanwhile, ZnO films grown by a similar PEALD process using a less bulky diethylzinc precursor, showed good crystallinity even with a higher growth rate of $2.0 \AA$ per cycle at $150{ }^{\circ} \mathrm{C} .{ }^{32}$ Considering the aforementioned information, we suspect that the low active surface site coverage by the bulky indium precursor and the relatively high growth rate of $\mathrm{InO}_{x}$ during the PEALD process would hinder crystal formation. Further work should be carried out to attain a better understanding of the detailed film growth mechanism.

After annealing at $350{ }^{\circ} \mathrm{C}$ under $\mathrm{O}_{2}$ conditions, (222), (400), and (440) peaks, an indium oxide bixbyite cubic structure, appears at all deposition temperatures because atoms would be rearranged with the given thermal energy. In addition, the peak intensity increases according to the deposition temperature and all peaks slightly shifted to a higher angle in comparison with the standard value of an indium oxide cubic structure (PDF\#06-0416). The peak shifts to a higher angle are due to structural shrinkage caused by unintentional Si doping or physical stress.

The optical properties of the $\mathrm{InO}_{x}$ films are depicted in Fig. 5. All the films show high transparency over $85 \%$ in a wavelength range of $450-800 \mathrm{~nm}$ and are comparable to the reported values as shown in the inset of Fig. 5. The transmittance of the film slightly decreases as the film deposition temperature increases, except for at $100{ }^{\circ} \mathrm{C}$. The optical transmittance of the oxide films is related to the carrier concentration therein. As the carrier concentration increases, optical absorption is also increased. ${ }^{33}$ Therefore, the transmittance results are consistent with the XPS data, which show a smaller amount of oxygen vacancies in the film deposited at $150{ }^{\circ} \mathrm{C}$, as well as Hall measurements which will be presented later. We adopt the Tauc method to extract the optical energy of each film. ${ }^{34}$ The optical band gap energies of each film are determined

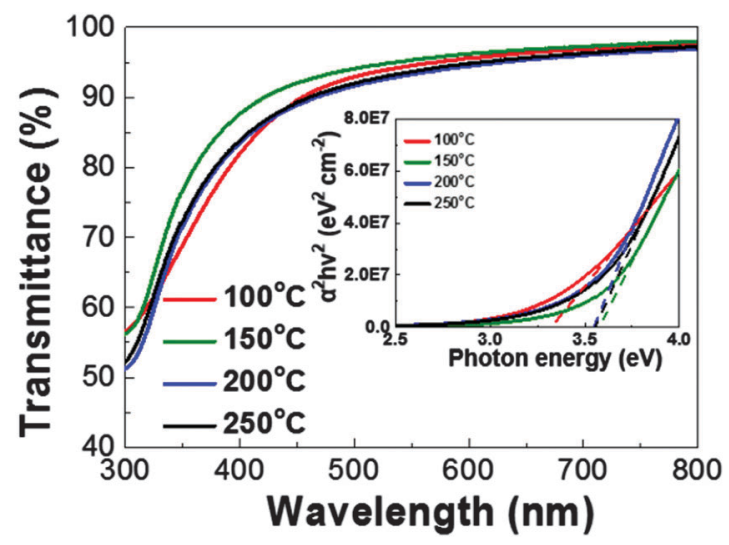

Fig. 5 Transmittance data of the annealed films deposited at a range of $100-250{ }^{\circ} \mathrm{C}$ by UV-vis analysis. The inset figure is a Tauc plot for extracting the optical band gap of the films. 
at the point where the linear fit (dotted lines) graphs cross the $x$ axis. This analysis yields values of $3.5-3.6 \mathrm{eV}$, consistent with reported values. ${ }^{1}$

For the application of the oxide film to the semiconducting material of TFTs, the electrical properties are critical. We measured the carrier concentration, Hall mobility, and resistivity of each film of $\mathrm{InO}_{x}$ before and after annealing at $350{ }^{\circ} \mathrm{C}$ under an $\mathrm{O}_{2}$ environment. The data for the non-annealed film deposited at $100{ }^{\circ} \mathrm{C}$ could not be obtained owing to its high resistivity and difficulty in forming an ohmic contact with the measurement system. In the case of the as-deposited films, as shown in Fig. 6(a), the Hall mobility and carrier density rose as the substrate temperature increased while the resistivity showed an opposite trend. In particular, the $\mathrm{InO}_{x}$ film prepared at $250{ }^{\circ} \mathrm{C}$ showed a Hall mobility and carrier density up to $34.3 \mathrm{~cm}^{2} \mathrm{~V}^{-1} \mathrm{~s}^{-1}$ and $-1.6 \times 10^{19} \mathrm{~cm}^{-3}$, respectively. The negative sign indicates that the major carriers in the film are electrons.

As for the annealed films (Fig. 6(b)), the trends of the carrier density and Hall mobility change, depending on the film growth temperature, are the same as those of the as-deposited films. However, the carrier density of the film is higher and the Hall mobility is lower than those of the as-deposited films at any of the growth temperatures. Typically, oxygen diffusion into the polycrystalline oxide is not as effective as into amorphous film, as reported by Kamiya et $a .^{35}$ Thermal annealing induces crystallization of $\mathrm{InO}_{x}$ and this would delay diffusion of oxygen molecules into the $\mathrm{InO}_{x}$ films. Meanwhile, partially oxidized $\mathrm{Si}$ incorporated into the $\mathrm{InO}_{x}$ would oxidize further within the $\mathrm{InO}_{x}$ to generate more oxygen vacancies around the In metal. We are currently investigating the origin of the increased carrier density in our $25 \mathrm{~nm} \mathrm{InO}_{x}$ films after thermal annealing.
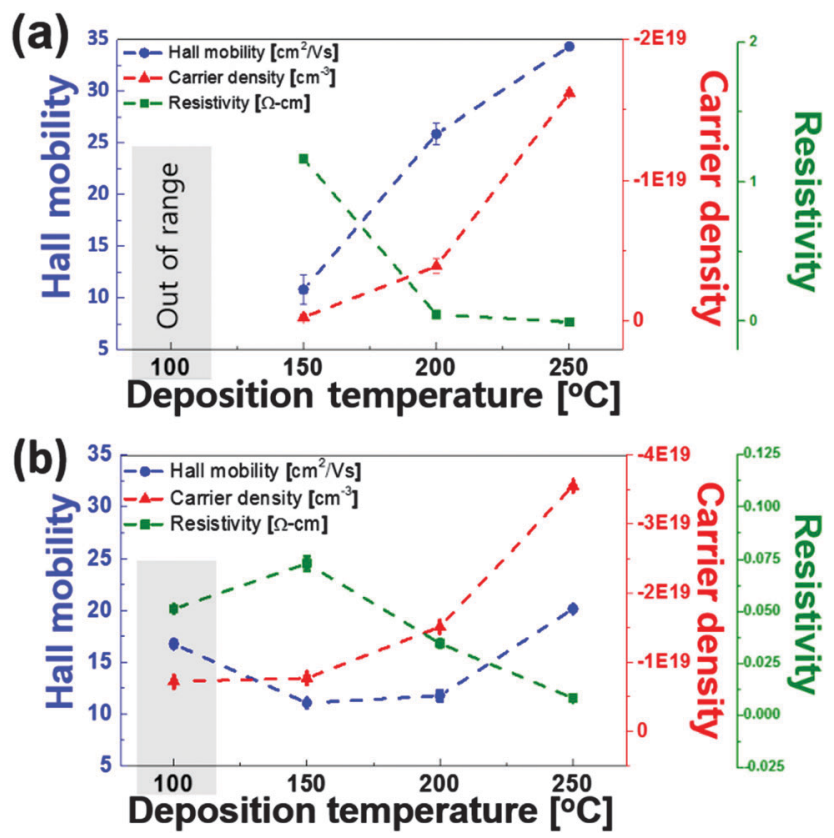

Fig. 6 The carrier density, Hall mobility and resistivity of (a) as-deposited indium oxide films and (b) films after annealing at $350{ }^{\circ} \mathrm{C}$ under $\mathrm{O}_{2}$ conditions.
The carrier density of the film gradually increases with increasing deposition temperature to a value as high as $-3.5 \times 10^{19} \mathrm{~cm}^{-3}$. This is consistent with the results for the amount of oxygen vacancies from the XPS data and the optical property. It has been reported that In interstitials $\left(\mathrm{In}_{\mathrm{i}}\right)$, especially In interstitials near oxygen vacancies $\left(\mathrm{V}_{\mathrm{O}}\right)$, are the likely source of high conductivity in indium oxide. ${ }^{36-38}$ The Hall mobility of the film deposited at $150{ }^{\circ} \mathrm{C}$ shows the lowest value of $11.05 \mathrm{~cm}^{2} \mathrm{~V}^{-1} \mathrm{~s}^{-1}$, whereas the other films show mobility as high as $20.15 \mathrm{~cm}^{2} \mathrm{~V}^{-1} \mathrm{~s}^{-1}$ at the deposition temperature of $250{ }^{\circ} \mathrm{C}$. The increase of the Hall mobility at higher deposition temperatures is attributed to the increased carrier density generated from shallow donors in the $\mathrm{InO}_{x}$ films. It is well known that the Hall mobility of an oxide semiconductor is proportional to the carrier density up to a certain degree due to percolation. ${ }^{39}$ The resistivity of the films is continuously reduced to a value as low as $8.73 \times 10^{-3} \Omega \mathrm{cm}$ as the growth temperature increases, except at $100{ }^{\circ} \mathrm{C}$. It is difficult to explain its abnormal behaviour in the film deposited at $100{ }^{\circ} \mathrm{C}$ due to the considerable amount of contaminants caused by the non-perfect ALD process. Although the annealed samples generally presented a lower Hall mobility than the non-annealed set due to the polycrystalline structure, all the films show a relatively lower carrier concentration, higher Hall mobility, and 1-2 orders of magnitude higher resistivity compared to the TCO $\mathrm{InO}_{x}$ film deposited by a thermal ALD process reported by Maeng et al. ${ }^{22}$

For the application of indium oxide to a semiconductor material, controlling the amount of carriers in the entire film plays a key role in the $V_{\text {on }}$ control, and Hall mobility is very important in obtaining high mobility of TFTs. In this light, our PEALD InO $_{x}$ films would be suitable as semiconducting oxide materials. We adopt the PEALD $\mathrm{InO}_{x}$ films deposited at $200{ }^{\circ} \mathrm{C}$ and $250{ }^{\circ} \mathrm{C}$ as the channel layer for bottom-gate coplanar oxide TFTs (Fig. 7(a)). To optimize the amount of carriers in the $\mathrm{InO}_{x}$ active layer, the film thickness is chosen as $5 \mathrm{~nm}$ since a carrier density reaching $\sim 4 \times 10^{19} \mathrm{~cm}^{-3}$ is too high to be fully depleted with a thick active semiconductor in the TFT. For this reason, we carried out thermal annealing of the $5 \mathrm{~nm} \mathrm{InO}_{x}$ film under $\mathrm{O}_{2}$ conditions since oxygen molecules could be fully diffused into the very thin active layer to reduce the amount of oxygen vacancies around the In metal. The bottom-gate coplanar $\mathrm{InO}_{x}$ TFT with a semiconductor film thicker than $10 \mathrm{~nm}$ was not modulated by applying a gate voltage (not shown here). Before evaluating the TFT characteristics, we obtained HRTEM images to verify the crystallinity of the thin $5 \mathrm{~nm} \mathrm{InO}_{x}$ films deposited at $200{ }^{\circ} \mathrm{C}$ and $250{ }^{\circ} \mathrm{C}$. HRTEM images of a crosssectional view of the stacked films of $\mathrm{Al}_{2} \mathrm{O}_{3} / \mathrm{InO}_{x} / \mathrm{SiO}_{2}$, which mimicked real devices, are shown in Fig. 7(b) and (c). We can observe that a poly-crystallized indium oxide partially exists within the amorphous $\mathrm{InO}_{x}$ phase. A closer view of both films reveals clear lattice fringes in the $\mathrm{InO}_{x}$ layers.

Fig. 8(a) and (b) show the drain current-drain voltage $\left(I_{\mathrm{d}}-V_{\mathrm{d}}\right)$ output characteristics of our $\mathrm{InO}_{x}$ TFTs fabricated at temperatures of $200{ }^{\circ} \mathrm{C}$ (IO-200) and $250{ }^{\circ} \mathrm{C}$ (IO-250). The measuring devices have a width and length of $20 \mu \mathrm{m}$ and $40 \mu \mathrm{m}$, respectively. Both devices exhibited well-saturated behavior under various gate voltages. There seem to be no contact issues between the $\mathrm{InO}_{x}$ layer and the S/D ITO electrodes since the 
(a)

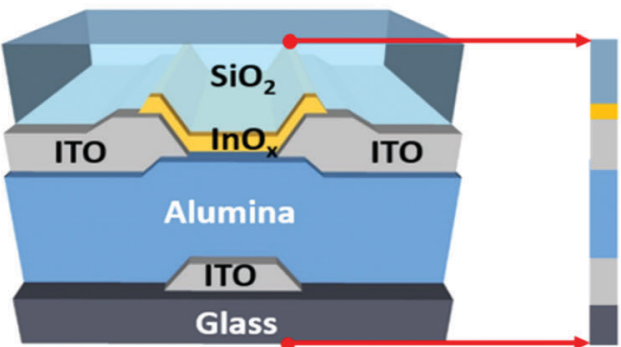

100nm : Passivation

$5 \mathrm{~nm}$ : Active layer

$150 \mathrm{~nm}$ : Source/Drain

$175 \mathrm{~nm}$ : Gate insulator

$150 \mathrm{~nm}$ : Source/Drain

Substrate

(b)

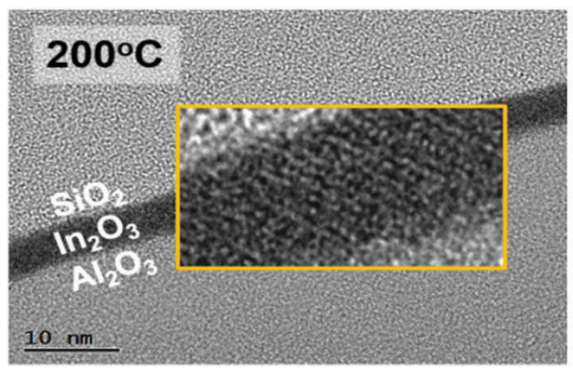

(c)

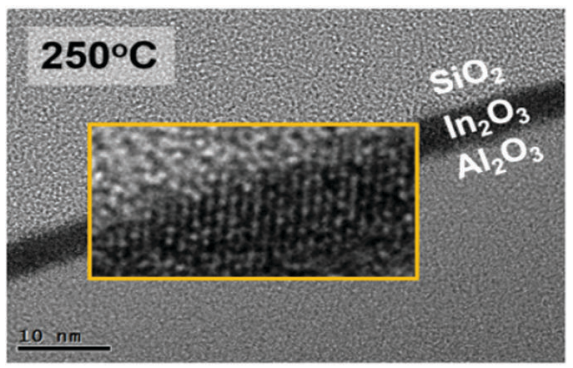

Fig. 7 (a) Bottom-gate coplanar TFT structure with a $5 \mathrm{~nm}$-thick indium oxide channel layer deposited at $200{ }^{\circ} \mathrm{C}$ and $250{ }^{\circ} \mathrm{C}$. HRTEM images of stacked films $\left(\mathrm{Al}_{2} \mathrm{O}_{3} / \mathrm{In}_{2} \mathrm{O}_{3} / \mathrm{SiO}_{2}\right)$, where $5 \mathrm{~nm}$-thick $\mathrm{InO}_{x}$ layers are deposited at (b) $200{ }^{\circ} \mathrm{C}$ and (c) $250{ }^{\circ} \mathrm{C}$. Each enlarged inset reveals the part of $\operatorname{lnO} \mathrm{O}_{x}$ layer with clear lattice fringes.

drain current is linearly increased at the low drain voltage $\left(V_{\mathrm{d}}\right)$ region, and all the curves converged to zero when $V_{\mathrm{d}}$ approaches zero in both devices. The saturated drain current

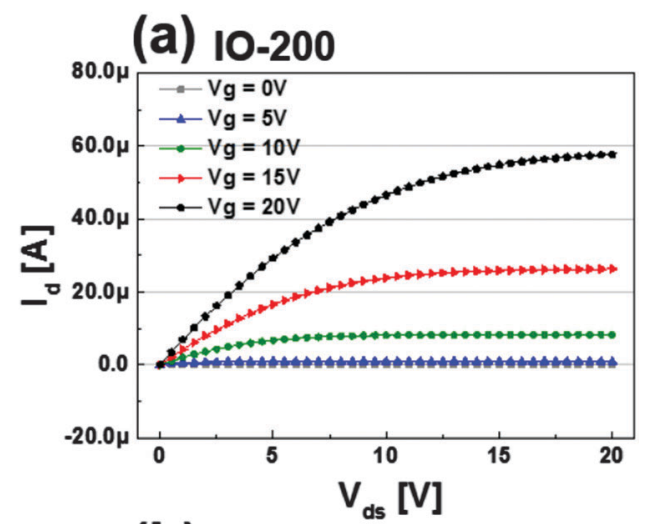

(b) $10-250$

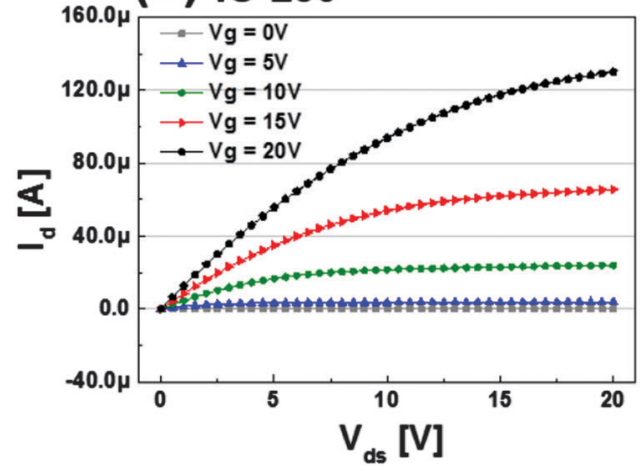

Fig. 8 Output characteristics of bottom-gate coplanar TFTs with a PEALD- $\operatorname{lnO} \mathrm{O}_{x}$ active layer deposited at (a) $200{ }^{\circ} \mathrm{C}$ and (b) $250{ }^{\circ} \mathrm{C}$. The channel width and length are $20 \mu \mathrm{m}$ and $40 \mu \mathrm{m}$, respectively. of IO-250 is more than twice as high as that of IO-200, indicating better driving capability.

Fig. 9 displays the transfer characteristics (drain to source current $I_{\mathrm{ds}}$ as a function of gate to source voltage $V_{\mathrm{gs}}$ ) of each TFT at a drain voltage of $0.1 \mathrm{~V}$ and $10 \mathrm{~V}$. The electrical parameters of the TFTs such as the field-effect mobility $\left(\mu_{\mathrm{FE}}\right)$, sub-threshold swing (S.S.), and on-to-off ratio are extracted in the linear regime at a drain voltage of $0.1 \mathrm{~V}$. The field-effect mobility is calculated as follows:

$$
\mu_{\mathrm{FE}}=\frac{g_{\mathrm{m}}}{\frac{W}{L} \cdot C_{i} \cdot V_{\mathrm{ds}}} \quad\left(\text { where } g_{\mathrm{m}}=\frac{\partial I_{\mathrm{ds}}}{\partial V_{\mathrm{gs}}}\right)
$$

The gate dielectric capacitance $\left(C_{i}\right)$ of the device was $4.24 \times 10^{-8} \mathrm{~F} \mathrm{~cm}^{-2}$, measured by a LCR meter using a metalinsulator-metal (MIM) structure (not shown here). In the case of IO-200, the field-effect mobility is $25.21 \mathrm{~cm}^{2} \mathrm{~V}^{-1} \mathrm{~s}^{-1}$, showing fairly good performance with a low S.S. value of $0.09 \mathrm{~V} \mathrm{dec}^{-1}$ and a turn-on voltage of $-0.14 \mathrm{~V}$. On the other hand, IO-250 showed a high mobility of $39.19 \mathrm{~cm}^{2} \mathrm{~V}^{-1} \mathrm{~s}^{-1}$, while exhibiting a larger swing value of $0.27 \mathrm{~V} \mathrm{dec}^{-1}$ and a negatively shifted turnon voltage $\left(V_{\text {on }}\right)$ of $-1.18 \mathrm{~V}$ compared to the former device. The average values of each parameter are summarized in a bar graph in Fig. 10. The TFTs were fabricated repeatedly and they all showed very high repeatability and uniformity. The $V_{\text {on }}$ of the oxide TFT is related to the mobility of the TFTs with the same device structure. As the mobility increases, the $V_{\text {on }}$ shifts to a negative voltage for full depletion of large carrier amounts in the active layer. ${ }^{40}$ Since the PEALD-IO film deposited at $250{ }^{\circ} \mathrm{C}$ has abundant $\operatorname{In}_{\mathrm{i}}$ and $\mathrm{V}_{\mathrm{O}}$-related shallow donors, resulting in large carrier amounts even in the $5 \mathrm{~nm}$-thick film, a more negative gate voltage should be applied to deplete the electron carriers in the channel. 

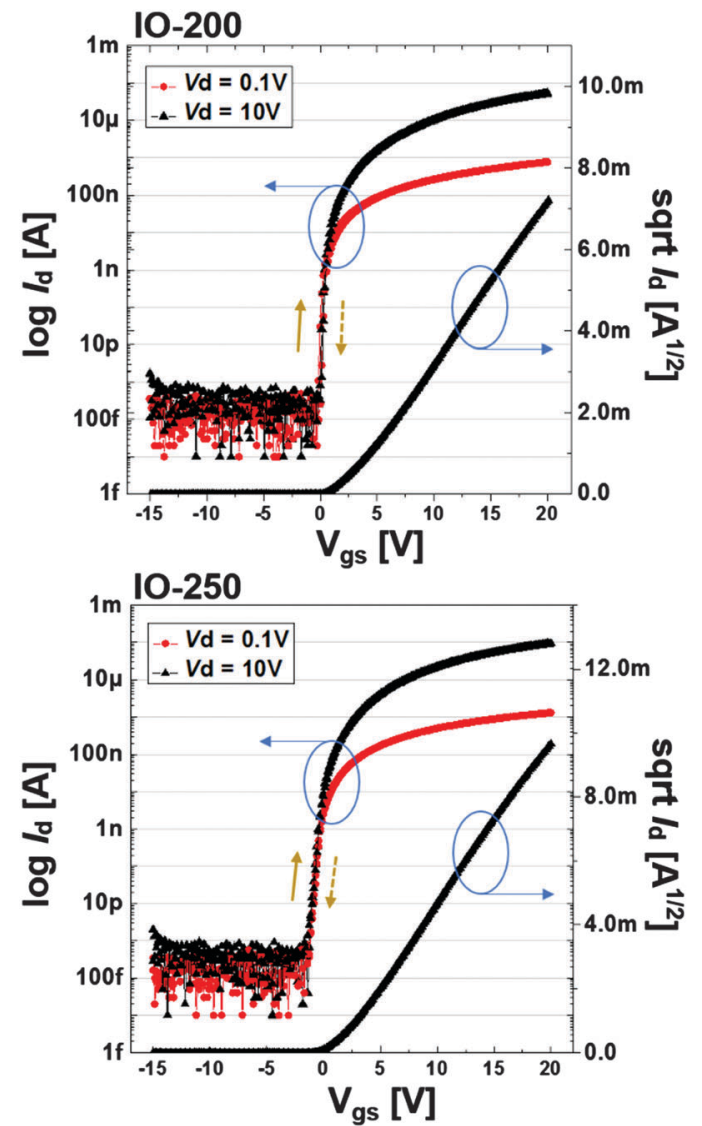

Fig. 9 Transfer characteristics of bottom-gate coplanar TFTs with a PEALD- $\operatorname{lnO} O_{x}$ active layer deposited at (a) $200{ }^{\circ} \mathrm{C}$ and (b) $250{ }^{\circ} \mathrm{C}$. The channel width and length are $20 \mu \mathrm{m}$ and $40 \mu \mathrm{m}$, respectively. The capacitance per unit area of the gate dielectric is $42.4 \mathrm{nF} \mathrm{cm}{ }^{-2}$.



Fig. 10 The average field-effect mobility, subthreshold swing, and turn-on voltage of $10-200$ and $10-250$.

In terms of the higher S.S. value for IO-250, we suspect that there are more oxygen-vacancy related states in the active layers. The $\mathrm{InO}_{x}$ film deposited at $250{ }^{\circ} \mathrm{C}$ contains greater donor-like states related to the oxygen vacancies which have been partially located near the conduction band edges. When the negative gate voltage is applied to deplete the carriers in the channel, the donor-like states should be empty to be positively charged and act as charge trap sites when applying a positive gate bias to deteriorate the S.S. characteristics of the TFT. Furthermore, as the film growth temperature increases, less oxygen-coordinated Si would be generated, which leads to an acceptor-like state. ${ }^{41}$ Nonetheless, the $\mathrm{InO}_{x}$ TFT fabricated by
PEALD shows superior performance in terms of mobility, high on/off ratio, $V_{\text {on }}$, and S.S. value compared to other $\operatorname{InO}_{x}$ TFTs reported to date.

Although amorphous oxide semiconductor TFTs are known to have high mobility, ${ }^{42}$ PEALD-InO ${ }_{x}$ TFTs showed an excellent electrical driving and switching performance even with nanocrystalline grains in the ultra-thin semiconducting layer. There could be several reasons for the fairly strong performances of our devices. One plausible cause is the large amount of carriers, which can overcome the potential barrier at the grain boundary. Another possibility is the percolation path induced by the linear chain of $\mathrm{InO}_{6}$ octahedra that can exist in both amorphous and crystalline phases. The indium cation is surrounded by six oxygen atoms and two structural vacancies, forming $\mathrm{InO}_{6}$ octahedra, and the neighboring $\mathrm{InO}_{6}$ octahedra can share either an edge or a corner. ${ }^{43}$ The edge sharing structures shorten the In-In distance, enhancing the capability for charge transport to yield a Hall mobility of more than $160 \mathrm{~cm}^{2} \mathrm{~V}^{-1} \mathrm{~s}^{-1}$. Thereby, electrons would likely take the current path that is formed by the connected $\mathrm{InO}_{6}$ polyhedra network even in the boundary regions.

\section{Conclusions}

Indium oxide thin films are successfully deposited by PEALD with a liquid $\mathrm{Et}_{2} \mathrm{InN}\left(\mathrm{SiMe}_{3}\right)_{2}$ precursor and oxygen plasma in the temperature range of $100-250{ }^{\circ} \mathrm{C}$. The growth rate is as high as $\sim 1.45 \AA$ per cycle, which exceeds that of other reported ALD-InO ${ }_{x}$ processes. The nano-crystalline $\mathrm{InO}_{x}$ films obtained by thermal annealing under $\mathrm{O}_{2}$ show a higher carrier density as the deposition temperature increases from $150{ }^{\circ} \mathrm{C}$ to $250{ }^{\circ} \mathrm{C}$. The main origin of carrier generation in $\mathrm{InO}_{x}$ is the more oxygen deficient bonding at a higher growth temperature. The bottom-gate coplanar structured $\mathrm{InO}_{x}$ TFTs are fabricated at active deposition temperature of $200{ }^{\circ} \mathrm{C}$ and $250{ }^{\circ} \mathrm{C}$ with precise control of the active film thickness, post-thermal annealing, and passivation process to optimize the $V_{\text {on }}$. The devices show a high linear mobility of $39 \mathrm{~cm}^{2} \mathrm{~V}^{-1} \mathrm{~s}^{-1}$ in spite of the nanopolycrystalline channel layer at a deposition temperature of $250{ }^{\circ} \mathrm{C}$. This shows the promise of the PEALD $\mathrm{InO}_{x}$ thin films as the active layer of next generation high performance oxide TFTs.

\section{Acknowledgements}

This research has been performed as a cooperation project of project no. KK1502-H00 (Development of Organometallics and Device Fabrication for IT ET Convergence) and supported by the Korea Research Institute of Chemical Technology (KRICT), and also supported by 'The cross-Ministry Giga KOREA project' grant from the Ministry of Science, ICT and Future Planning, Korea [GK15D0100].

\section{References}

1 R. L. Weiher, J. Appl. Phys., 1966, 37, 299.

2 R. L. Weiher, J. Appl. Phys., 1962, 33, 2834.

3 R. B. H. Tahar, T. Ban, Y. Ohya and Y. Takahashi, J. Appl. Phys., 1997, 82, 865. 
4 L. Wang, M.-H. Yoon, G. Lu, Y. Yang, A. Facchetti and T. J. Marks, Nat. Mater., 2006, 5, 893.

5 B. Macco, Y. Wu, D. Vanhemel and W. M. M. Kessels, Phys. Status Solidi RRL, 2014, 8, 987.

6 J. H. Noh, S. Y. Ryu, S. J. Jo, C. S. Kim, S.-W. Sohn, P. D. Rack, D.-J. Kim and H. K. Baik, IEEE Electron Device Lett., 2010, 31, 567.

7 H. Z. Zhang, H. T. Cao, A. H. Chen, L. Y. Liang, Z. M. Liu and Q. Wan, Solid-State Electron., 2010, 54, 479.

8 Dhananjay and C.-W. Chu, Appl. Phys. Lett., 2007, 91, 132111.

9 F. Gherendi, M. Nistor, S. Antohe, L. Ion, I. Enculescu and N. B. Mandache, Semicond. Sci. Technol., 2013, 28, 085002.

10 Y. Meng, G. Liu, A. Liu, H. Song, Y. Hou, B. Shin and F. Shan, RSC Adv., 2015, 5, 37807.

11 H. Park, Y. Nam, J. Jin and B.-S. Bae, RSC Adv., 2015, 5, 102362.

12 A. Liu, G. X. Liu, H. H. Zhu, F. Xu, E. Fortunato, R. Martins and F. K. Shan, ACS Appl. Mater. Interfaces, 2014, 6, 17364.

13 Y. Vygranenko, K. Wang and A. Nathan, Appl. Phys. Lett., 2007, 91, 263508.

14 D. Kekuda, K. M. Rao, A. Tolpadi, C. W. Chu, A. B. Garg, R. Mittal and R. Mukhopadhyay, AIP Conf. Proc., 2011, 1349, 1081.

15 T. Asikainen, M. Ritala and M. Leskela, J. Electrochem. Soc., 1994, 141, 3210.

16 O. Nilsen, R. Balasundaraprabhu, E. V. Monakhov, N. Muthukumarasamy, H. Fjellvag and B. G. Svensson, Thin Solid Films, 2009, 517, 6320.

17 R. K. Ramachandran, J. Dendooven, H. Poelman and C. Detavernier, J. Phys. Chem. C, 2015, 119, 11786.

18 D.-J. Lee, J.-Y. Kwon, J. I. Lee and K.-B. Kim, J. Phys. Chem. C, 2011, 115, 15384.

19 J. W. Elam, A. B. F. Martinson, M. J. Pellin and J. T. Hupp, Chem. Mater., 2006, 18, 3571.

20 J. H. Han, E. A. Jung, H. Y. Kim, D. H. Kim, B. K. Park, J.-S. Park, S. U. Son and T.-M. Chung, Appl. Surf. Sci., 2016, 383, 1.

21 W. J. Maeng, D.-W. Choi, J. Park and J.-S. Park, J. Alloys Compd., 2015, 649, 216.

22 W. J. Maeng, D. W. Choi, K. B. Chung, W. Koh, G. Y. Kim, S. Y. Choi and J. S. Park, ACS Appl. Mater. Interfaces, 2014, 6, 17481 .
23 J. W. Lim and S. J. Yun, Electrochem. Solid-State Lett., 2004, 7, F45.

24 J. L. van Hemmen, S. B. S. Heil, J. H. Klootwijk, F. Roozeboom, C. J. Hodson, M. C. M. van de Sanden and W. M. M. Kessels, J. Electrochem. Soc., 2007, 154, G165.

25 W.-H. Kim, W. J. Maeng, K.-J. Moon, J.-M. Myoung and H. Kim, Thin Solid Films, 2010, 519, 362.

26 H. S. Nalwa, Handbook of thin film materials, Academic Press, San Diego, USA, 2002.

27 J. W. Klaus, S. J. Ferro and S. M. George, Thin Solid Films, 2000, 360, 145.

28 R. L. Puurunen, J. Appl. Phys., 2005, 97, 121301.

29 S. E. Potts, W. Keuning, E. Langereis, G. Dingemans, M. C. M. van de Sanden and W. M. M. Kessels, J. Electrochem. Soc., 2010, 157, P66.

30 N. Mitoma, S. Aikawa, X. Gao, T. Kizu, M. Shimizu, M.-F. Lin, T. Nabatame and K. Tsukagoshi, Appl. Phys. Lett., 2014, 104, 102103.

31 A. Kushwaha and M. Aslam, J. Phys. D: Appl. Phys., 2013, 46, 485104.

32 S.-H. K. Park, C.-S. Hwang, H.-S. Kwack, J.-H. Lee and H. Y. Chu, Electrochem. Solid-State Lett., 2006, 9, G299.

33 H. Peelaers, E. Kioupakis and C. G. Van de Walle, Appl. Phys. Lett., 2012, 100, 011914.

34 B. D. Viezbicke, S. Patel, B. E. Davis and D. P. Birnie, III, Phys. Status Solidi B, 2015, 252, 1700.

35 K. Watanabe, D.-H. Lee, I. Sakaguchi, K. Nomura, T. Kamiya, H. Haneda, H. Hosono and N. Ohashi, Appl. Phys. Lett., 2013, 103, 201904.

36 S. Lany and A. Zunger, Phys. Rev. Lett., 2007, 98, 045501.

37 P. Agoston, P. Erhart, A. Klein and K. Albe, J. Phys.: Condens. Matter, 2009, 21, 455801.

38 T. Tomita, K. Yamashita, Y. Hayafuji and H. Adachi, Appl. Phys. Lett., 2005, 87, 051911.

39 T. Kamiya and H. Hosono, NPG Asia Mater., 2010, 2, 15.

40 S.-J. Lee, C.-S. Hwang, J.-E. Pi, J.-H. Yang, C.-W. Byun, H. Y. Chu, K.-I. Cho and S. H. Cho, ETRI J., 2015, 37, 1135.

41 A. V. Kimmel, P. V. Sushko, A. L. Shluger and G. GBersuker, ECS Trans., 2009, 19, 3.

42 T. Kamiya, K. Nomura and H. Hosono, J. Disp. Technol., 2009, 5, 273.

43 D. B. Buchholz, Q. Ma, D. Alducin, A. Ponce, M. JoseYacaman, R. Khanal, J. E. Medvedeva and R. P. H. Chang, Chem. Mater., 2014, 26, 5401. 